\title{
The relation between serum parathyroid hormone (PTH) and blood pressure. The Tromsø study
}

\author{
Rolf Jorde \\ Institute of Clinical Medicine, University of Tromsø, Tromsø, Norway \\ Correspondence: Rolf Jorde, Medical Department B, University Hospital of North Norway, NO-9038 Tromsø, Norway \\ Telephone: +4777626827 Telefax:+4777626863 E-mail: rolf.jorde@unn.no
}

\begin{abstract}
The objective of the present cross-sectional epidemiological study from Tromsø, North Norway was to evaluate the relation between blood pressure and serum parathyroid hormone (PTH). 10419 subjects were invited to participate in the fifth Tromsø study and 8128 attended. 7954 subjects had serum PTH measured, and among these, information on blood pressure medication was available in 5841 subjects (2554 males) with serum calcium within the reference range 2.20-2.60 mmol/L. In a multiple linear regression model with age, BMI, serum calcium, serum creatinine, and smoking status as covariables, serum PTH was a significant and positive predictor of systolic and diastolic blood pressure in both genders. When dividing the cohort in PTH quartiles, and adjusting for age, BMI, serum calcium, and serum creatinine, the differences between the lowest and highest PTH quartile in systolic and diastolic blood pressure were 5.0 and $3.5 \mathrm{mmHg}$ for males and 4.1 and $2.5 \mathrm{mmHg}$ for females, respectively. In previous studies we have found serum PTH to be a positive predictor for future increase in blood pressure, and also that the association between serum PTH and blood pressure cannot alone be ascribed to a blood pressure induced increase in urinary calcium excretion. To further elucidate the relation between serum PTH and blood pressure, randomized clinical trials with calcium and/or vitamin D supplementation to subjects with increased serum PTH levels are needed.
\end{abstract}

\section{INTRODUCTION}

Parathyroid hormone (PTH) is a peptide hormone secreted from the parathyroid glands. The secretion of PTH is mainly regulated by the extra-cellular ionized calcium level through a negative feed-back mechanism. Thus, a high ionized calcium level reduces the PTH secretion, and conversely, a fall in ionized calcium increases the PTH secretion. PTH in turn increases the serum calcium level by increasing bone resorption and the renal tubular calcium absorption. In addition, PTH stimulates the hydroxylation of $25(\mathrm{OH})$ vitamin D to its active metabolite $1.25(\mathrm{OH})_{2}$ vitamin $\mathrm{D}$, which in turn leads to increased calcium absorption from the intestines (1).

PTH binds to specific receptors that not only exist on the surface of its major target organs bone and kidney cells, but also on the cell membrane of a number of other organs such as the nervous system and the heart (2). In this way, excessive PTH secretion can have a multitude of effects, and PTH has been implicated in disease states like neuropathy and left ventricular hypertrophy (2).

There are both epidemiological and experimental data linking calcium metabolism to the regulation of blood pressure. Thus, a low calcium intake is associated with an increase in blood pressure $(3,4)$, whereas calcium supplementation appears to have a blood pressure lowering effect (5). Similarly, supplementation with vitamin D, both to elderly women (6) as well as middle-aged men (7), has been reported to significantly reduce the blood pressure.

In subjects with a calcium deficit, there is a compensatory increase in the secretion of PTH. One would therefore expect a positive association between serum PTH and blood pressure, which has been reported from most (8-11), but not all studies (12).

There are also indications for a causal relation between PTH and blood pressure. Thus, subjects with primary hyperparathyroidism, where the high serum PTH level is caused by a parathyroid adenoma, have increased blood pressure (13), and chronic infusion of PTH has been reported to cause hypertension (14).

Thus, if there is a causal relation between PTH and blood pressure, one would expect those with elevated serum PTH to increase their blood pressure more over time than those with normal PTH levels. In particular, one would expect those who increased their PTH levels to have the highest increase in blood pressure at a later examination, which was demonstrated by us in a recent study (15).

The Tromsø study, which is a health survey focusing on cardiovascular diseases, was performed for the first time in 1974 (16), and has since then been repeated with 6-8 years interval. In the fifth Tromsø study in 2001 serum PTH was measured in 7954 subjects, among whom 1784 also had serum PTH measured in the fourth Tromsø study in 1994/1995. Accordingly, a 
large database was available for a cross-sectional as well as a longitudinal study of the relation between serum PTH and blood pressure. We here report the cross-sectional results for the first time, and also summarize the results of the longitudinal study which has been published in more detail previously (15).

\section{MATERIALS AND METHODS}

In the fourth Tromsø study 1994-1995 all men and women aged $>24$ years who were living in the municipality of Tromsø, which is the major city in North Norway, were invited to participate. A subgroup was invited to a second phase that included blood samples for hormone analysis. In 2001 all men and women older than 29 years, living in the same area, and that participated in the second phase of the fourth Tromsø study or became $30,40,45,60$ or 75 years old during 2001, were invited to participate in the fifth Tromsø study.

On both occasions a questionnaire including use of blood pressure medication and smoking status was filled in. Smokers were classified as current smokers or current non-smokers. Height, weight, and blood pressure were measured as previously described (17). Body mass index (BMI) was calculated as weight $(\mathrm{kg})$ divided by squared height $(\mathrm{m})$. Blood samples were drawn in the non-fasting state and analysed for serum calcium and creatinine within two months, and for serum PTH within 12 months. All samples were stored frozen at $-70{ }^{\circ} \mathrm{C}$. The analytic methods were as reported before (17). In our laboratory the reference range for serum calcium is $2.20-2.60 \mathrm{mmol} / \mathrm{L}$, for serum PTH 1.1-6.8 pmol/L for those $<51$ years and 1.1-7.5 $\mathrm{pmol} / \mathrm{L}$ for those $>50$ years, and serum creatinine 55 $100 \square \mathrm{mol} / \mathrm{L}$ for women and $70-120 \square \mathrm{mol} / \mathrm{L}$ for men.

\section{Statistics}

In the statistical analyses only subjects with serum calcium in the range $2.20-2.60 \mathrm{mmol} / \mathrm{L}$ and not using anti-hypertensive medication, were included. Normal distribution was evaluated with visual inspection of histograms and determination of skewness and kurtosis, and all variables used as dependent variables were considered normally distributed.

A multiple linear regression model was used to assess gender, age, BMI, smoking status, serum calcium, serum creatinine, and serum PTH as independent predictors of systolic and diastolic blood pressure. There was a significant effect of gender, and males and females were evaluated separately. Linear trends across PTH quartiles were tested with linear regression with use of covariates as above. A general linear model was used to calculate adjusted means for systolic and diastolic blood pressure in the PTH quartiles.

Unless otherwise stated, all data are expressed as mean $\pm \mathrm{SD}$. All tests were done two-sided, and $P<$ 0.05 was considered statistically significant. Statistical analyzes were performed with SPSS version 11.0 (SPSS Inc, Chicago, IL., USA).

\section{RESUlts}

10419 subjects were invited to participate in the fifth Tromsø study and 8128 attended. 7954 subjects had serum PTH measured. Among these, 7794 subjects answered the question on blood pressure medications and 6239 were present non-users. 352 subjects had serum calcium $<2.20 \mathrm{mmol} / \mathrm{L}$ and 46 subjects had serum calcium $>2.60 \mathrm{mmol} / \mathrm{L}$, leaving 5841 subjects (2554 males) for the present study. The demographics of these 5841 subjects are given in Table 1.

Table 1. Characteristics of the study population.

\begin{tabular}{lcc}
\hline & Males & Females \\
\hline $\mathrm{N}$ & 2554 & 3287 \\
Age (years) & $57.3 \pm 14.5$ & $57.2 \pm 14.3$ \\
BMI $\left(\mathrm{kg} / \mathrm{m}^{2}\right)$ & $26.6 \pm 3.6$ & $26.1 \pm 4.4$ \\
Systolic blood pressure $(\mathrm{mmHg})$ & $137.3 \pm 19.0$ & $134.1 \pm 22.3$ \\
Diastolic blood pressure $(\mathrm{mmHg})$ & $80.5 \pm 11.3$ & $77.5 \pm 12.1$ \\
Serum PTH $(\mathrm{pmol} / \mathrm{L})$ & $3.3 \pm 1.5$ & $3.3 \pm 1.5$ \\
Serum calcium $(\mathrm{mmol} / \mathrm{L})$ & $2.36 \pm 0.07$ & $2.36 \pm 0.08$ \\
Serum creatinine $(\square \mathrm{mol} / \mathrm{L})$ & $96.2 \pm 11.9$ & $81.9 \pm 9.6$ \\
Current smokers $(\%)$ & 30.8 & 30.0 \\
\hline
\end{tabular}

When the cohort was divided in PTH quartiles, there was in both genders a gradual increase in age, BMI, and serum creatinine with increasing PTH quartile, and a gradual decrease in serum calcium with increasing PTH quartile (Table 2). Similarly, there was in both genders a gradual and significant increase in systolic and diastolic blood pressure with increasing PTH quartile. The difference between the lowest and highest PTH quartile in age, BMI, serum creatinine, and serum calcium adjusted systolic and diastolic blood pressure, were for males 5.0 and $3.5 \mathrm{mmHg}$, respectively, and for females 4.1 and $2.5 \mathrm{mmHg}$, respectively (Table 3 ).

In the multiple linear regression model, serum PTH was a positive and significant predictor of systolic and diastolic blood pressure in both genders (Table 4).

\section{DISCUSSION}

In the present study we have found a significant and positive association between serum PTH and both systolic and diastolic blood pressure in both genders. In addition, there was an increase in age and BMI with increasing PTH quartile. Both age and BMI are positively associated with blood pressure, but the association between serum PTH and blood pressure was still highly significant after correction for these variables and also when serum calcium and creatinine were included in the regression model.

The relation between blood pressure and PTH has been studied by several other authors, and in most studies the results are in accordance with ours (8-11). 
Table 2. Age, BMI, serum calcium and serum creatinine in relation to serum PTH quartile and gender.

\begin{tabular}{llccccc}
\hline & & & & $\begin{array}{c}\text { BMI } \\
\left(\mathrm{kg} / \mathrm{m}^{2}\right)\end{array}$ & $\begin{array}{c}\text { Serum calcium } \\
(\mathrm{mmol} / \mathrm{L})\end{array}$ & $\begin{array}{c}\text { Serum creatinine } \\
(\mathrm{mol} / \mathrm{L})\end{array}$ \\
\hline \multirow{2}{*}{ Males } & PTH quartile 1 (0-2.2 pmol/L) & 623 & $53.6 \pm 14.9$ & $26.3 \pm 3.4$ & $2.38 \pm 0.07$ & $95.0 \pm 9.9$ \\
& PTH quartile 2 (2.3-3.0 pmol/L) & 640 & $56.2 \pm 14.7$ & $26.4 \pm 3.4$ & $2.36 \pm 0.07$ & $95.2 \pm 10.9$ \\
& PTH quartile 3 (3.1-4.0 pmol/L) & 664 & $58.5 \pm 14.1$ & $26.6 \pm 3.7$ & $2.35 \pm 0.07$ & $96.2 \pm 11.0$ \\
& PTH quartile 4 $(>4.0 \mathrm{pmol} / \mathrm{L})$ & 627 & $60.7 \pm 13.5$ & $27.0 \pm 3.7$ & $2.34 \pm 0.08$ & $98.5 \pm 14.8$ \\
Females & & & & & & \\
& PTH quartile 1 (0-2.2 pmol/L) & 857 & $53.5 \pm 15.0$ & $25.5 \pm 4.0$ & $2.38 \pm 0.08$ & $80.7 \pm 8.9$ \\
& PTH quartile 2 (2.3-3.0 pmol/L) & 836 & $56.5 \pm 13.5$ & $25.9 \pm 4.3$ & $2.36 \pm 0.08$ & $81.3 \pm 9.1$ \\
& PTH quartile 3 (3.1-4.0 pmol/L) & 780 & $59.3 \pm 13.9$ & $26.2 \pm 4.4$ & $2.36 \pm 0.08$ & $82.4 \pm 9.7$ \\
& PTH quartile 4 (>4.0 pmol/L) & 814 & $59.8 \pm 14.0$ & $26.8 \pm 4.9$ & $2.34 \pm 0.08$ & $83.5 \pm 10.6$ \\
\hline
\end{tabular}

Table 3. Unadjusted and adjusted systolic and diastolic blood pressure in relation to serum PTH quartile and gender.

\begin{tabular}{llccccc}
\hline & & & Systolic BP \\
& & $\mathrm{N}$ & $\begin{array}{c}\text { Adjusted }^{1} \\
\text { systolic BP } \\
(\mathrm{mmHg})\end{array}$ & $\begin{array}{c}\text { Diastolic BP } \\
(\mathrm{mmHg})\end{array}$ & $\begin{array}{c}\text { Adjusted }^{1} \\
\text { diastolic BP } \\
(\mathrm{mmHg})\end{array}$ \\
\hline Males & PTH quartile 1 (0-2.2 pmol/L) & 623 & $133.3 \pm 18.2$ & $134.6 \pm 17.7$ & $78.5 \pm 11.1$ & $78.8 \pm 11.0$ \\
& PTH quartile 2 (2.3-3.0 pmol/L) & 640 & $135.5 \pm 17.3$ & $135.9 \pm 17.2$ & $79.5 \pm 10.5$ & $79.7 \pm 10.6$ \\
& PTH quartile 3 (3.1-4.0 pmol/L) & 664 & $139.2 \pm 19.6$ & $138.5 \pm 17.1$ & $81.1 \pm 11.2$ & $80.8 \pm 10.5$ \\
& PTH quartile 4 (> 4.0 pmol/L) & 627 & $141.0 \pm 19.8^{2}$ & $139.6 \pm 17.7$ & $82.7 \pm 11.9^{2}$ & $82.3 \pm 11.0$ \\
Females & PTH quartile 1 (0-2.2 pmol/L) & 857 & $129.8 \pm 20.5$ & $132.5 \pm 18.4$ & $75.9 \pm 11.8$ & $76.4 \pm 11.3$ \\
& PTH quartile 2 (2.3-3.0 pmol/L) & 836 & $132.9 \pm 22.0$ & $133.4 \pm 18.4$ & $77.1 \pm 11.7$ & $77.2 \pm 11.3$ \\
& PTH quartile 3 (3.1-4.0 pmol/L) & 780 & $135.4 \pm 22.1$ & $133.7 \pm 18.8$ & $77.8 \pm 11.7$ & $77.3 \pm 11.6$ \\
& PTH quartile 4 (> 4.0 pmol/L) & 814 & $138.8 \pm 23.7^{2}$ & $136.7 \pm 18.8$ & $79.5 \pm 12.7^{2}$ & $79.0 \pm 11.6$ \\
\hline
\end{tabular}

${ }^{1}$ Adjusted for age, BMI, serum calcium, and serum creatinine

${ }^{2} \mathrm{P}<0.001$, linear trend with age, BMI, smoking status, serum calcium, and serum creatinine as covariables

Table 4. Standardized $\square$ and $t$ values in the multiple linear regression model in the 2554 males and 3287 females.

\begin{tabular}{|c|c|c|c|c|c|c|c|c|}
\hline & \multicolumn{4}{|c|}{ Dependent variable systolic blood pressure } & \multicolumn{4}{|c|}{ Dependent variable diastolic blood pressure } \\
\hline & \multicolumn{2}{|c|}{ Males } & \multicolumn{2}{|c|}{ Females } & \multicolumn{2}{|c|}{ Males } & \multicolumn{2}{|c|}{ Females } \\
\hline & B & $t$ & $\beta$ & $t$ & $\beta$ & $t$ & B & $t$ \\
\hline Age (years) & 0.39 & 20.47 & 0.51 & 33.38 & 0.23 & 11.84 & 0.22 & 12.43 \\
\hline BMI $\left(\mathrm{kg} / \mathrm{m}^{2}\right)$ & 0.10 & 5.28 & 0.11 & 7.42 & 0.20 & 10.14 & 0.15 & 8.84 \\
\hline Serum PTH $(\mathrm{pmol} / \mathrm{L})$ & 0.09 & 4.72 & 0.05 & 3.36 & 0.11 & 5.43 & 0.08 & 4.50 \\
\hline Serum calcium $(\mathrm{mmol} / \mathrm{L})$ & 0.11 & 5.64 & 0.11 & 7.05 & 0.12 & 6.00 & 0.15 & 8.60 \\
\hline Serum creatinine $(\square \mathrm{mol} / \mathrm{L})$ & -0.01 & -0.49 & -0.02 & -1.28 & -0.04 & -2.07 & 0.00 & 0.12 \\
\hline Smoking status ${ }^{1}$ & 0.05 & 2.55 & 0.01 & 0.96 & 0.02 & 0.98 & -0.02 & -1.23 \\
\hline
\end{tabular}

${ }^{1}$ Smokers $=1$, non-smokers $=2$

Values of $|t|>1.96,|t|>2.58$, and $|t|>3.29$ correspond to $P<0.05, P<0.01$, and $P<0.001$, respectively

Thus, in the study by John et al. (10) that included 583 subjects, and in the study by Landin-Wilhelmsen et al. (11) that included 347 subject, a positive association between serum PTH and blood pressure was found. However, in a study by Zachariah et al. (12) no significant association between serum PTH and blood pressure was found, but that study only included 27 hypertensive subjects and focused primarily on diastolic blood pressure. We therefore find it fair to conclude that the positive association between serum PTH and blood pressure now is firmly established.

If this relation is causal, one would expect subjects with a high serum PTH level to have a higher increase in their blood pressure over time than subjects with lower serum PTH levels, and also that subjects with an increase in serum PTH would experience a corresponding increase in blood pressure. We have recently addressed that issue in an analysis of 1784 subjects with 
serum PTH measurements in both the fourth Tromsø study in 1994/1995 and in the fifth Tromsø study in 2001 (15). In that study the serum PTH level in the males in the fourth Tromsø study was a positive and significant predictor of the delta systolic blood pressure (blood pressure in 2001 minus blood pressure in 1994/1995). Thus, the difference in delta systolic blood pressure between those in the highest and those in the lowest PTH quartile from 1994/1995 was 3.5 mmHg. Furthermore, in males the delta serum PTH (serum PTH from 2001 minus serum PTH from 1994/1995) was a significant predictor of delta systolic blood pressure. In the females the same trend was found, but did not reach statistical significance (15).

These findings add to the growing number of indications that PTH is associated with the development of hypertension. However, statistical associations are no proof of a causal relation, and could simply reflect covariation with factors not measured so far. Furthermore, if there is a causal relation, hypertension could induce a PTH increase just as well as an elevated PTH level could increase the blood pressure. Regarding the latter possibility, intravenous infusion of PTH over a two hour period caused an increase in blood pressure in healthy male subjects (18), as did a 12-day chronic PTH infusion in another group of normal subjects (14). However, when the ionized calcium level was kept constant during the PTH infusion with a clamping technique, Jespersen et al. (19) found a moderate blood pressure lowering effect of intravenously infused PTH.

Conversely, the blood pressure could have an effect on the PTH level through its effect on the urinary excretion of calcium. Thus, more than $50 \%$ of the renal calcium reabsorption is passively linked to the absorption of sodium in the proximal tubule. Hypertension is associated with a high salt intake, which would lead not only to a high sodium excretion, but also to a high calcium excretion and consequently secondary hyperparathyroidism.

This appealing theory has been frequently cited $(11,20)$, but has so far not been substantiated. In a recent study we tested this hypothesis by evaluating the association between serum PTH and blood pressure in relation to excretion of creatinine, sodium, and calcium in a morning urine sample in 3620 subjects attending the fifth Tromsø study (21). We found an increa- sing urinary calcium/creatinine ratio with increasing blood pressure, but this ratio had no effect on the positive association between serum PTH and blood pressure in a multiple regression model. Furthermore, in a subanalysis on a large group of subjects having an almost identical urinary calcium excretion, there was still a highly significant and positive association between serum PTH and blood pressure. Accordingly, this association cannot alone be explained by a blood pressure induced increase in urinary calcium excretion.

A high serum PTH is only a marker of calcium deficit, and other variables like intakes of calcium and/or vitamin $\mathrm{D}$, as well as levels of serum ionised calcium and serum 25-(OH)vitamin $\mathrm{D}$ may be the causative one(s) regarding blood pressure, and not PTH. Furthermore, the intake of calcium as well as vitamin D is in parallel with other nutrients, and it is well known that the high degree of intercorrelation among dietary factors makes it difficult to identify the importance of single factors (22).

However, there are several mechanisms by which PTH might affect the blood pressure. Thus, PTH activates the renal 1-alpha-hydroxylase resulting in increased 1.25- $(\mathrm{OH})_{2}$ vitamin D levels which again increases the calcium influx into vascular smooth muscle cells, causing an increase in vascular tone and blood pressure (23). Furthermore, PTH has been reported to have a prosclerotic effect on vascular smooth muscle cells (24), which may contribute to vessel wall thickening and arteriosclerosis.

In conclusion, there are strong indications for a causal relationship between an increased PTH level and elevated blood pressure. To prove this relationship, one would have to move from epidemiology to intervention studies and demonstrate a reduction in blood pressure after normalization of PTH in a group of subjects with elevated PTH levels. However, this has so far not been conclusively demonstrated in a large group of subjects, and the clinical implication of the blood pressure and parathyroid hormone association is therefore yet to be determined.

\section{ACKNOWLEDGEMENTS}

The present study was supported by a grant from the Norwegian Research Council.

\section{REFERENCES}

1. McCarron DA, Morris CD, Henry HJ, Stanton JL. Blood pressure and nutrient intake in the United States. Science 1984; 224: 1392-1398.

2. Bro S, Olgaard K. Effects of excess PTH on nonclassical target organs. Am J Kidney Dis 1997; 30: 606-620.

3. Cappuccio FP, Elliott P, Allender PS, Pryer J, Follman DA, Cutler JA. Epidemiologic association between dietary calcium intake and blood pressure: A meta-analysis of published data. Am J Epidemiol 1995; 142: 935-945.

4. Bucher HC, Cook RJ, Guyatt GH, et al. Effects of dietary calcium supplementation on blood pressure. A meta-analysis of randomized controlled trials. JAMA 1996; 275: 1016-1022. 
5. Pfeifer M, Begerow B, Minne HW, Nachtigall D, Hansen C. Effects of a short-term vitamin $\mathrm{D}_{3}$ and calcium supplementation on blood pressure and parathyroid hormone levels in elderly women. J Clin Endocrinol Metab 2001; 86: 1633-1637.

6. Lind L, Pollare T, Hvarfner A, Lithell H, Sørensen OH, Ljunghall S. Long-term treatment with active vitamin D (alphacalcidol) in middle-aged men with impaired glucose tolerance. Effects on insulin secretion and sensitivity, glucose tolerance and blood pressure. Diabetes Res 1989; 11: 141-147.

7. Bouillon R, Carmeliet G, Boonen S. Ageing and calcium metabolism. Baillieres Clin Endocrinol Metab 1997; 11: 341-365.

8. Brickman A, Nyby M, von Hungen K, Eggena P, Tuck M. Parathyroid hormone, platelet calcium, and blood pressure in normotensive subjects. Hypertension 1991; 18: 176-182.

9. Young EW, McCarron DA, Morris CD. Calcium regulating hormones in essential hypertension. Importance of gender. Am J Hypertens 1990; 3: 161S-166S.

10. St John A, Dick I, Hoad K, Retallack R, Welborn T, Prince R. Relationship between calcitrophic hormones and blood pressure in elderly subjects. Eur J Endocrinol 1994; 130: 446-450.

11. Landin-Wilhelmsen K, Wilhelmsen L, Lappas G, et al. Serum intact parathyroid hormone in a random population sample of men and women: relationship to anthropometry, life-style factors, blood pressure and vitamin D. Calcif Tissue Int 1995; 56: 104-108.

12. Zachariah PK, Schwartz GL, Strong CG, Ritter SG. Parathyroid hormone and calcium. A relationship in hypertension. Am J Hypertens 1988; 1: 79S-82S.

13. Andersson P, Rydberg E, Willenheimer R. Primary hyperparathyroidism and heart disease - a review. Eur Heart J 2004; 25:1776-1787.

14. Hulter HN, Melby JC, Peterson JC, Cooke CR. Chronic continuous PTH infusion results in hypertension in normal subjects. J Clin Hypertens 1986; 2: 360-370.

15. Jorde R, Svartberg J, Sundsfjord J. Serum parathyroid hormone as a predictor of increase in systolic blood pressure in men. J Hypertens 2005; 23: 1639-1644.

16. Thelle DS, Førde OH, Try K, Lehmann EH. The Tromsø heart study: methods and main results of the crosssectional study. Acta Med Scand 1976; 200: 107-118.

17. Jorde R, Bønaa KH, Sundsfjord J. Population based study on serum ionised calcium, serum parathyroid hormone, and blood pressure. The Tromsø Study. Eur J Endocrinol 1999; 141: 350-357.

18. Fliser D, Franek E, Fode P, et al. Subacute infusion of physiological doses of parathyroid hormone raises blood pressure in humans. Nephrol Dial Transplant 1997; 12: 933-938.

19. Jespersen B, Randløv A, Abrahamsen J, Fogh-Andersen N, Kanstrup IL. Effects of PTH (1-34) on blood pressure, renal function, and hormones in essential hypertension. The altered pattern of reactivity may counteract raised blood pressure. Am J Hypertens 1997; 10: 1356-1367.

20. Nordin BEC, Need AG, Morris HA, et al. The nature and significance of the relationship between urinary sodium and urinary calcium in women. J Nutr 1993; 123: 1615-1622.

21. Saleh F, Jorde R, Svartberg J, Sundsfjord J. The relation between blood pressure and serum parathyroid hormone with special reference to urinary calcium excretion. The Tromsø study. J Endocrinol Invest 2006; 29: 214-220.

22. Reed D, McGee D, Yano K, Hankin J. Diet, blood pressure, and multicollinearity. Hypertension 1985; 7: 405-410.

23. Zemel MB. Calcium modulation of hypertension and obesity: mechanisms and implications. Am Coll Nutr 2001; 20: 428S-435S.

24. Perkovic V, Hewitson TD, Kelynack KJ, Martic M, Tait MG, Becker GJ. Parathyroid hormone has a prosclerotic effect on vascular smooth muscle cells. Kidney Blood Press Res 2003; 26: 27-33. 